\title{
The association between objectively measured physical activity and morning symptoms in COPD
}

\author{
This article was published in the following Dove Press journal: \\ International Journal of COPD \\ 3 October 2017 \\ Number of times this article has been viewed
}

\author{
Amanda $R$ van Buul' \\ Marise J Kasteleyn ${ }^{1,2}$ \\ Niels H Chavannes ${ }^{2}$ \\ Christian Taube ${ }^{1,3}$ \\ 'Department of Pulmonology, \\ ${ }^{2}$ Department of Public Health \\ and Primary Care, Leiden \\ University Medical Center, Leiden, \\ the Netherlands; ${ }^{3}$ Department of \\ Pulmonary Medicine, West German \\ Lung Center, Essen University \\ Hospital, Ruhrlandklinik, University \\ Duisburg-Essen, Essen, Germany
}

Correspondence: Amanda R van Buul Department of Pulmonology, Postzone C2-R, Leiden University Medical Center, Albinusdreef 2, Postbus 9600, 2300 RC Leiden, the Netherlands

Tel +3 I 715298726

$\mathrm{Fax}+3|7| 5266927$

Email a.r.van_buul@lumc.nl
Purpose: The morning is the most bothersome period for COPD patients. Morning symptom severities in different Global Initiative for Chronic Obstructive Lung Disease (GOLD) stages are not well studied. Furthermore, factors that are associated with morning symptoms, especially the associations with objectively measured physical activity, are also not well described.

Materials and methods: The aim of this cross-sectional observational study was to assess morning symptom severity in GOLD A, B, C and D patients, according to the definitions of the GOLD 2015 statement. Morning symptoms were assessed with the PRO-Morning COPD Symptoms Questionnaire. Differences in morning symptom severity between different COPD stages were assessed with a one-way analysis of variance followed by post hoc analyses. The association between dyspnea severity (assessed with the modified Medical Research Council scale), health status, airflow limitation, lung hyperinflation, anxiety and depression, inflammatory parameters, exacerbations, objectively measured physical activity parameters retrieved from accelerometry and morning symptom severity was evaluated using linear regression analysis. Results: Eighty patients were included (aged 65.6 \pm 8.7 years, forced expiratory volume in 1 second $\left[\mathrm{FEV}_{1}\right] \%$ predicted $\left.55.1 \pm 16.9\right)$. Mean ( $\left.\pm \mathrm{SD}\right)$ morning symptom score was $19.7( \pm 11.7)$. Morning symptom severity was significantly different between COPD stages: mean $( \pm \mathrm{SD})$ score in GOLD A was $9.7( \pm 7.2)$, in GOLD B $19.8( \pm 10.7)$, in GOLD C $8.6( \pm 9.3)$ and in GOLD D $23.8( \pm 11.2)(p<0.001)$. Lower health status, more symptoms, increased anxiety and depression, less physical activity (all $p<0.001)$ and lower $\operatorname{FEV}_{1}(p=0.03)$ were associated with an increased morning symptom severity.

Conclusion: Patients with overall more symptomatic COPD have significant higher morning symptom scores. Morning symptom severity was associated with important clinical outcomes: lower health status, more symptoms, increased anxiety and depression, fewer steps a day, less time in moderate and vigorous physical activity with bouts of at least 10 minutes and lower FEV . $_{\text {. }}$ The data suggest that morning symptoms should be carefully assessed in addition to assessment by general COPD-specific questionnaires, especially in those with more symptomatic COPD. More research is needed on potential therapies to improve morning symptoms; this study shows potential targets for intervention.

Keywords: accelerometry, chronic obstructive pulmonary disease, physical activity, PROMorning COPD Symptoms Questionnaire, morning symptoms

\section{Introduction}

COPD is the fifth leading cause of disability-adjusted life-years worldwide. ${ }^{1}$ COPD is characterized by airway obstruction, lung emphysema and chronic inflammation of the airways. Airway obstruction is usually progressive over time but variability over short time is low. Still, COPD symptoms vary throughout the day. ${ }^{2}$ In recent years, 
it has become apparent that the morning is the most symptomatic part of the day for most COPD patients. ${ }^{3}$ A recent review showed that the occurrence of morning symptoms in COPD varies widely from $38.9 \%$ up to $94.4 \%$ of patients and morning symptoms are present in all COPD severity classes. ${ }^{4}$ However, the prevalence of morning symptoms seems to be heavily dependent on the used questionnaire. ${ }^{5}$ In addition, few studies assessed the severity of morning symptoms in relation to COPD severity and identified factors that are associated with morning symptoms. ${ }^{2,6,7}$

One of the important factors in COPD patients is physical activity. People with COPD are more physically inactive compared to their healthy peers. ${ }^{8,9}$ This is also reflected in the observation that only $26 \%$ to $30 \%$ of patients with COPD fulfilled the WHO physical activity recommendations. ${ }^{10,11}$ The lack of sufficient physical activity is associated with more exacerbations, hospitalizations, all-cause mortality ${ }^{12}$ and lower quality of life. ${ }^{13}$ The aetiology of physical inactivity in COPD patients is not completely understood. The lack of activity could be due to the avoidance of pulmonary symptoms, or it can be speculated that physical activity could be a risk factor to develop COPD. Self-reported low physical activity has been shown as a factor that is related with morning symptoms. ${ }^{2}$ Half of the patients reported that they had made changes in morning routines, even in simple tasks, due to symptoms. ${ }^{14}$ However, to our knowledge, no studies have been done that evaluate the relationship between objectively measured physical activity by triaxial accelerometry and morning symptoms.

The primary objective of the Morning symptoms in-Depth observAtional Study (MODAS) was to assess the severity of morning symptoms in different Global Initiative for Obstructive Lung Disease (GOLD) stages. The secondary objective was to evaluate the association between dyspnea severity, health status, airflow limitation, lung hyperinflation, anxiety and depression, inflammatory parameters, exacerbations, objectively measured physical activity parameters and morning symptom severity. We hypothesized that patients in more advanced GOLD stages have higher morning symptom scores. Furthermore, we expect that morning symptom severity will be negatively associated with physical activity.

\section{Materials and methods Study design}

The MODAS was a single center, observational, cross-sectional study that was conducted from September 2015 until February 2017 in the Netherlands. The medical ethics committee from the Leiden University Medical Center (LUMC) approved the study (protocol number NL51951.058.15).

\section{Study subjects}

Outpatients were recruited from a university medical center (the LUMC), a regional hospital (the Alrijne hospital) and were recruited by distributing flyers in local papers. Interested patients received the study information by letter. Upon agreeing to participate, a visit was scheduled. All patients gave written informed consent.

Patients were eligible if they had a diagnosis of COPD by a physician, met the criteria for GOLD II-IV according to the definitions of the GOLD statement ${ }^{15}$ and were aged 40 to 80 years, a general symptomatic patient group. Furthermore, they had to be current smokers or ex-smokers with a lifetime tobacco exposure of $\geq 10$ pack years. Patients were excluded if they had a diagnosis of asthma, history of sensitization to allergens or significant other lung disease. In addition, patients were excluded if they had comorbidities that significantly impaired exercise capacity in the opinion of the investigator (eg, severe polyneuropathy, leg amputation). Other exclusion criteria were current malignant diseases or clinical signs of acute heart failure. Patients with mental impairment that could result in noncompliance with the study protocol were also excluded. Also, patients who were currently enrolled in a rehabilitation program or with an exacerbation in the previous 2 months were excluded. An exacerbation was defined as sustained worsening of respiratory symptoms during 48 hours and requiring oral corticosteroid, antibiotic or a combination of this treatment that was initiated by a physician, a visit to the emergency department or hospitalization with or without intensive care visit. Respiratory symptoms included at least one of the Anthonisen criteria (increased dyspnea, sputum volume and sputum purulence). ${ }^{16}$

\section{Study procedures and outcomes}

The study consisted of one visit to the study center. Patients were interviewed by a physician about their employment status, smoking status and COPD exacerbations in the previous year. Furthermore, morning symptoms, dyspnea severity, health status and pulmonary function were assessed and blood was drawn. All pulmonary function tests were performed between 8.30 and 11.00 AM. Immediately following this visit, the patients wore a triaxial accelerometer for 7 consecutive days. To collect information regarding possible adverse events, patients were contacted by telephone after these 7 days. 
The occurrence and severity of morning symptoms were assessed with the PRO-Morning COPD Symptoms Questionnaire. ${ }^{17}$ This questionnaire consists of six questions. Patients rated the severity of dyspnea, sputum production, chest tightness, wheezing and cough in the morning with a Likert scale ranging from 0 to 10 points for each question: 0 points represent no symptoms and 10 points represent symptoms as severe as they can imagine. Limitations in the morning due to COPD were scored with the same Likert scale. Total morning symptom scores ranged from 0 to 60 . A total score of 0 indicated no symptoms at all in the morning.

The American College of Sports Medicine (ACSM) and the American Heart Association stated that adults should perform moderate-intensity physical activity for a minimum of 30 minutes (or bouts of at least 10 minutes) for 5 days each week or vigorous-intensity physical activity for a minimum of 20 minutes on 3 days each week..$^{18}$ To objectively measure physical activity, patients wore a validated triaxial accelerometer (Dynaport MoveMonitor; McRoberts BV, The Hague, the Netherlands) ${ }^{19-21} 24$ hours a day for 7 consecutive days after baseline visit. Due to non-water resistance, patients were not allowed to wear the accelerometer while taking a shower or a bath. Body posture and types of physical activity, as well the duration and intensity of the activity were measured. Steps, total duration of active and inactive periods, active time in light (1.5-3.0 metabolic equivalent task $[\mathrm{MET}])$, moderate- (3.0-6.0 MET) and vigorousintensity (6.0-9.0 MET) activities, number of active and inactive periods and number of walking periods $\leq 10$ seconds, 10-20 seconds and $>20$ seconds were taken as secondary outcomes derived from the accelerometer. Additionally, to take the activity guidelines of the ACSM into account, active time in moderate physical activity (MPA), vigorous physical activity and moderate-to-vigorous physical activity (MVPA) in bouts of at least 10 minutes were measured. Activity was defined as standing, shuffling and walking combined; inactivity was defined as sitting and lying combined. Furthermore, the accelerometer measured the time that it was not worn.

Symptom burden was assessed with the modified Medical Research Council (mMRC) scale with scores ranging from 0 to $5 .^{22}$ Health status was assessed using the COPD assessment test (CAT) ${ }^{23}$ Comorbidity was evaluated with the Charlson Comorbidity index (CCI). ${ }^{24}$ High-sensitive C-reactive protein was measured in serum. Total leukocyte cell counts as well as absolute numbers of eosinophils were assessed. Lung function was assessed post-bronchodilator via spirometry (CareFusion, Masterscreen PFT System) following European Respiratory Society (ERS)/American Thoracic Society (ATS) standards. ${ }^{25}$ Forced vital capacity (FVC) and forced volume in one second $\left(\mathrm{FEV}_{1}\right)$ were expressed in absolute and $\%$ predicted values, respectively (based on Global Lung Function Initiative 2012). ${ }^{26}$ Total lung capacity and residual volume (RV) were measured by body box (CareFusion, Masterscreen Body), ${ }^{27}$ and RV was expressed in \% predicted values (based on European Community for Coal and Steel). To assess hyperinflation, the ratio between RV and TLC was calculated. Severity of COPD was reported as GOLD A-D based on symptoms assessed with the $\mathrm{mMRC}$, airway obstruction and exacerbations in the previous year ${ }^{15}$ (Supplementary materials).

\section{Statistical analysis}

Descriptive data were reported as mean values \pm standard deviations (SD) for continuous data with a normal distribution, median with interquartile ranges (IQR) for continuous data with a non-normal distribution or percentages for categorical data. To assess whether there was a normal distribution, histograms were made from each continuous individual variable and the shapes of the histograms were carefully assessed. Differences for age and gender between participants and nonparticipants were analyzed with an independent $t$-test and a chi-square test, respectively. Differences in morning symptom severity between COPD stages A, B, C and D were assessed with a one-way analysis of variance followed by post hoc analyses.

When the accelerometer was worn less than 22.5 hours a day (94\%), the day was excluded from analysis. Mean values derived from the accelerometer were calculated as the mean per patient only from valid days. When there was an adverse event for which a health care provider visit was required during the study period, the patient was excluded from activity analysis since adverse events might have negative effects on physical activity. The association between physical activity, dyspnea severity, health status, anxiety and depression, airflow limitation, lung hyperinflation, laboratory results, the presence of at least one exacerbation in the previous year and morning symptom severity was analyzed with univariable linear regression analysis. We looked at the overall explained variance $\left(R^{2}\right)$ of morning symptoms. In addition, regression analyses were adjusted for gender, age, ethnicity, body mass index, current smoking, number of exacerbations in the previous year, long-acting muscarinic antagonist (LAMA) use since LAMAs probably protect against morning symptoms, ${ }^{17}$ employment status and comorbidity measured with the CCI. Missing data were not replaced. For all analyses, a $p$-value of $<0.05$ was considered statistically significant. We used SPSS version 23 for the statistical analysis. 
A sensitivity analysis was performed to examine the impact of the CAT, instead of mMRC, to calculate GOLD classes A-D, since previous studies reported that the use of different questionnaires to categorize COPD patients can significantly alter the groups. ${ }^{28,29}$

\section{Results}

\section{Patients}

Of the 168 eligible patients who received the patient information letter, 80 patients agreed to participate. No significant differences between participants and nonparticipants were observed for age (mean $[ \pm \mathrm{SD}] 65.6[ \pm 8.7]$ and 66.3 [ \pm 8.4$]$ years, respectively, $p=0.79)$ and gender $(54 \%$ and $44.3 \%$ males, respectively, $p=0.22$ ). No patient dropped out of the study (Figure 1). Table 1 shows demographics and baseline characteristics of the participants. Patients had an airflow obstruction with an average $\mathrm{FEV}_{1}$ of $55.1 \%$ predicted, and $26 \%$ of the patients were current smokers.

\section{Morning symptoms}

Morning symptoms were present in $96 \%$ (77/80) of the patients. Mean $( \pm \mathrm{SD})$ total severity score for morning symptoms was 17.9 ( \pm 11.7$)$ (Table 2$)$. The most severe symptoms in the morning were dyspnea, cough and sputum production. Overall, $85.0 \%$ of all included patients reported physical activity limitations in the morning due to morning symptoms. Morning symptom scores were significantly different between patients with different COPD stages: mean $( \pm \mathrm{SD})$ score in GOLD A was $9.7( \pm 7.2)$, B $19.8( \pm 10.7)$, C $8.6( \pm 9.3)$

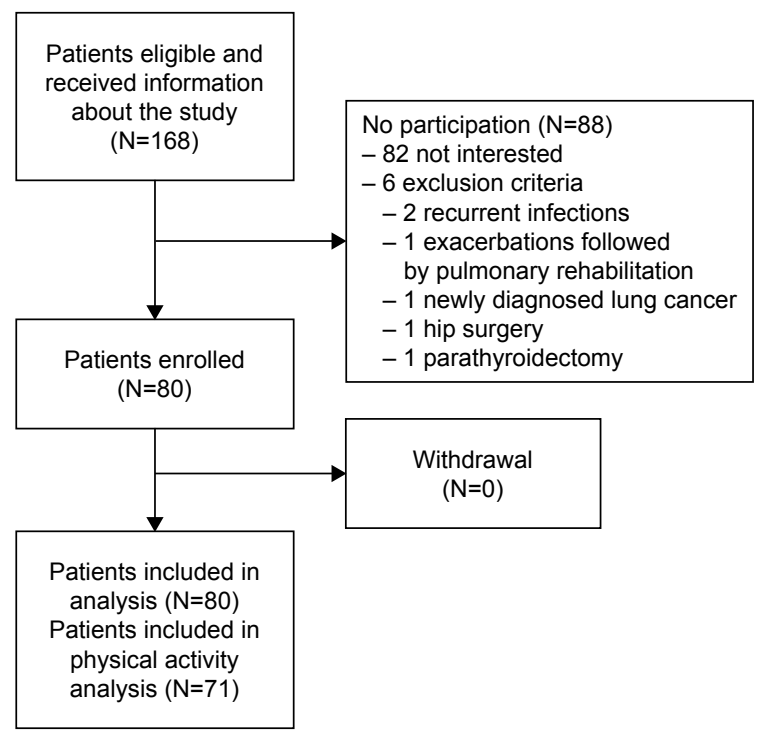

Figure I Study flow diagram.
Table I Baseline characteristics

\begin{tabular}{|c|c|}
\hline Characteristic & $\begin{array}{l}\text { COPD patients } \\
(\mathrm{N}=\mathbf{8 0})\end{array}$ \\
\hline \multicolumn{2}{|l|}{ General } \\
\hline Age in years, mean (SD) & $65.6(8.7)$ \\
\hline Male, $\mathrm{n}(\%)$ & $43(54 \%)$ \\
\hline Caucasian ethnicity, n (\%) & 79 (99\%) \\
\hline Current smoking, n (\%) & $21(26 \%)$ \\
\hline Pack years, mean (SD) & $42.2(26.8)$ \\
\hline Patients with exacerbation(s) in previous year, $\mathrm{n}(\%)$ & $42(53 \%)$ \\
\hline In current employment, n (\%) & $22(28 \%)$ \\
\hline $\mathrm{BMl}$ in $\mathrm{kg} / \mathrm{m}^{2}$, mean $(\mathrm{SD})$ & $26.3(5.1)$ \\
\hline \multicolumn{2}{|l|}{ Lung function (post-bronchodilator) } \\
\hline $\mathrm{FEV}, \%$ predicted, mean (SD) & $55.1(16.9)$ \\
\hline FVC in L, mean (SD) & $3.5(1.0)$ \\
\hline $\mathrm{RV} \%$ predicted, mean $(\mathrm{SD})^{\mathrm{a}}$ & $143(42)$ \\
\hline $\mathrm{RV} / \mathrm{TLC}$, mean $(\mathrm{SD})^{\mathrm{a}}$ & II $17(24)$ \\
\hline \multicolumn{2}{|l|}{ GOLD stage } \\
\hline GOLD A, n (\%) & $20(25 \%)$ \\
\hline GOLD B, n (\%) & $21(26 \%)$ \\
\hline GOLD C, n (\%) & $7(9 \%)$ \\
\hline GOLD D, n (\%) & $32(40 \%)$ \\
\hline \multicolumn{2}{|l|}{ Laboratory } \\
\hline Leucocytes in $\times 10^{9} / \mathrm{L}$, mean $(\mathrm{SD})$ & $8.3(2.5)$ \\
\hline Eosinophils in $\times 10^{9} / \mathrm{L}$, median [IQR] & $0.16[0.11-0.22]$ \\
\hline HsCRP in $\mathrm{mg} / \mathrm{L}$, median [IQR] & $2.41[0.26-5.42]$ \\
\hline \multicolumn{2}{|l|}{ Medication } \\
\hline ICS, n (\%) & $6(8 \%)$ \\
\hline LABA, n (\%) & $19(24 \%)$ \\
\hline LAMA, n (\%) & $60(75 \%)$ \\
\hline ICS+LABA, n (\%) & $50(63 \%)$ \\
\hline LABA+LAMA, n (\%) & $7(9 \%)$ \\
\hline Oral corticosteroids, $\mathrm{n}(\%)$ & $3(4 \%)$ \\
\hline \multicolumn{2}{|l|}{ Questionnaires } \\
\hline CAT total score, mean (SD) & $16.5(7.3)$ \\
\hline mMRC total score, mean (SD) & $2.4(1.3)$ \\
\hline $\mathrm{CCl}$ (total score), median [IQR] & $2.0[1.0-3.0]$ \\
\hline Myocardial infarction, $\mathrm{n}(\%)$ & $5(6 \%)$ \\
\hline Cerebrovascular disease, n (\%) & $10(13 \%)$ \\
\hline Uncomplicated diabetes mellitus, n (\%) & $9(11 \%)$ \\
\hline Moderate to severe chronic kidney disease, n (\%) & $6(8 \%)$ \\
\hline History of solid tumor without metastasis, n (\%) & $15(19 \%)$ \\
\hline HADS total score, mean (SD) ${ }^{\mathrm{a}}$ & $9.2(5.7)$ \\
\hline Depression & $4.7(3.8)$ \\
\hline Anxiety ${ }^{\mathrm{a}}$ & $4.5(3.2)$ \\
\hline
\end{tabular}

Notes: aFor some variables, data were missing: HADS (two patients did not fill out all questions about anxiety) and body plethysmography (three patients were not able to produce reproducibility curves and I patient had claustrophobia).

Abbreviations: BMI, body mass index; CAT, COPD assessment test; $\mathrm{CCl}$, Charlson comorbidity index; COPD, chronic obstructive pulmonary disease; $\mathrm{FEV}_{\text {, }}$, forced expiratory volume in I second; FVC, forced vital capacity; GOLD, Global Initiative for Chronic Obstructive Lung Disease; HADS, hospital anxiety and depression scale; hsCRP, high sensitive C-reactive protein; ICS, inhaled corticosteroids; IQR, interquartile range; LABA, long-acting beta2 agonist; LAMA, long-acting muscarinic antagonist; mMRC, modified Medical Research Council; RV, residual volume; SD, standard deviation; TLC, total lung capacity.

and D $23.8( \pm 11.2)(F[d f]=10.3[79], p<0.01)$ (Figure 2). Post hoc analyses showed differences between groups $\mathrm{A}$ and $\mathrm{B}(p<0.01)$, A and $\mathrm{D}(p<0.01), \mathrm{B}$ and $\mathrm{C}(p=0.013)$ and $\mathrm{C}$ and $\mathrm{D}(p<0.01)$. 
Table 2 Occurrence and severity of morning symptoms

\begin{tabular}{ll}
\hline Morning symptoms & $\mathbf{N}=\mathbf{8 0}$ \\
\hline Total score (range 0-60) ${ }^{\mathrm{a}}$, mean (SD) & $17.9(\mathrm{II} .7)$ \\
Number of patients without & $3(3.8 \%)$ \\
symptoms and limitations & \\
Sub-items & \\
Dyspnea & \\
Sputum & $4.0[1.3-6.0]$ \\
Chest tightness & $2.0[0.0-5.0]$ \\
Wheezing & $0.0[0.0-2.8]$ \\
Cough & $1.0[0.0-3.0]$ \\
Limitations in the morning due to COPD & $3.0[1.0-4.8]$ \\
\hline
\end{tabular}

Notes: Data are median [IQR], unless otherwise indicated. aMorning symptom score was assessed with the PRO-Morning COPD Symptoms Questionnaire; 'score 0 ("no symptoms") to 10 ("most worst symptoms").

Abbreviation: IQR, interquartile range.

\section{Physical activity}

Eight patients reported an adverse event during the study period (Table S1) and one patient wore the accelerometer for an insufficient time each day of the study (7.2 to 13.7 hours a day). Ninety-four percent of the measured days from the remaining 71 patients were included in the analysis. The median number of days analyzed per patient was seven. Table 3 shows outcomes derived from accelerometry. Patients walked an average of 5,754 steps a day, and they spent 11.4 minutes a day in MVPA with bouts of at least 10 minutes.

\section{Relationship between morning symptoms and other parameters}

Table 4 shows the association between baseline patient characteristics and morning symptom severity. When adjusted

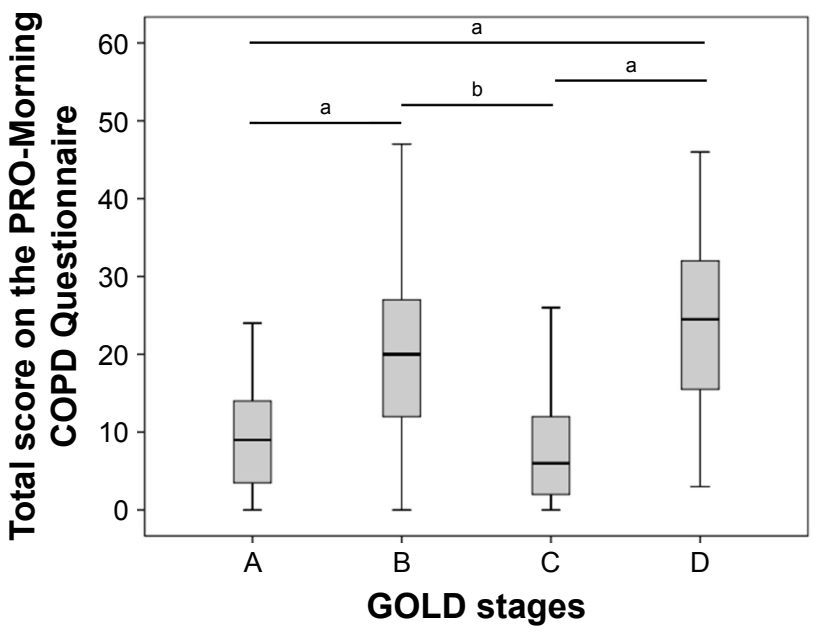

Figure 2 Morning symptom scores in COPD GOLD A, B, C and D groups. Notes: COPD GOLD A $(\mathrm{N}=20), B(\mathrm{~N}=2 \mathrm{I}), \mathrm{C}(\mathrm{N}=7)$ and $\mathrm{D}(\mathrm{N}=32) ;{ }^{a} p<0.0 \mathrm{l}$, ${ }^{\mathrm{b}} \mathrm{p}<0.05$.

Abbreviation: GOLD, Global Initiative for Chronic Obstructive Lung Disease.
Table 3 Daily physical activity parameters derived from accelerometry

\begin{tabular}{|c|c|}
\hline Activity parameters & $\begin{array}{l}467 \text { valid days }^{\mathrm{a}} \\
\text { from } 71 \text { patients }\end{array}$ \\
\hline \multicolumn{2}{|l|}{ Inactive parameters ${ }^{b}$} \\
\hline $\begin{array}{l}\text { Total duration in inactive time in minutes, } \\
\text { mean (SD) }\end{array}$ & $1,161(100)$ \\
\hline Number of periods in inactive time, mean (SD) & $128(42)$ \\
\hline \multicolumn{2}{|l|}{ Active parameters ${ }^{c}$} \\
\hline Steps, mean (SD) & $5,754(3,553)$ \\
\hline $\begin{array}{l}\text { Total duration in active time in minutes, } \\
\text { mean (SD) }\end{array}$ & $268(98)$ \\
\hline $\begin{array}{l}\text { Total duration in light activities in minutes, } \\
\text { mean (SD) }\end{array}$ & $80(33)$ \\
\hline $\begin{array}{l}\text { Total duration in moderate activities in minutes, } \\
\text { mean (SD) }\end{array}$ & $88(39)$ \\
\hline $\begin{array}{l}\text { Total duration of vigorous activities in minutes, } \\
\text { median }\left[{ }^{\mathrm{QQR}}\right]^{d}\end{array}$ & $0.9[0.3,6.2]$ \\
\hline $\begin{array}{l}\text { Mean active time in MVPA with bouts of at least } \\
10 \text { minutes, in minutes, median }[\mathrm{IQR}]^{d}\end{array}$ & II.4[4.4, 23.I] \\
\hline $\begin{array}{l}\text { Mean active time in moderate activity with bouts } \\
\text { of at least } 10 \text { minutes, in minutes, median [IQR }]^{d}\end{array}$ & II.5 $[4.3,22.1]$ \\
\hline $\begin{array}{l}\text { Mean active time in vigorous activity with bouts } \\
\text { of at least } 10 \text { minutes in minutes, median [IQR }]^{d}\end{array}$ & $0.0[0.0,0.0]$ \\
\hline Number of periods in active time, mean (SD) & $\mathrm{I}, 858(810)$ \\
\hline $\begin{array}{l}\text { Number of periods walking } \leq 10 \text { seconds, } \\
\text { mean (SD) }\end{array}$ & $317(139)$ \\
\hline $\begin{array}{l}\text { Number of periods walking } 10-20 \text { seconds, } \\
\text { mean (SD) }\end{array}$ & $70(37)$ \\
\hline $\begin{array}{l}\text { Number of periods walking }>20 \text { seconds, } \\
\text { median }[\mathrm{IQR}]\end{array}$ & $24[15,31]$ \\
\hline
\end{tabular}

Notes: ${ }^{a}$ Valid days were defined as accelerometry for at least 22.5 hours (94\%) a day; binactive: sitting and lying combined; cactive: standing, shuffling and walking combined; dight: 1.5-3.0 MET, moderate: 3.0-6.0 MET, vigorous: 6.0-9.0 MET.

Abbreviations: IQR, interquartile ranges; MET, metabolic equivalent task; MVPA, moderate to vigorous physical activity; SD, standard deviation.

for confounders, lower health status (estimated regression coefficient $=1.194,95 \%$ CI 0.923 to 1.465 ), higher symptomatic burden (estimated regression coefficient $=4.193$, $95 \%$ CI 2.384 to 6.002 ), increased anxiety and depression and lower FEV 1 were associated with morning symptom severity. Furthermore, physical activity that was objectively measured by accelerometry was associated with morning symptom severity: fewer steps a day (estimated regression coefficient $=-0.001,95 \% \mathrm{CI}-0.002$ to -0.000 ), less time in MVPA with bouts of at least 10 minutes (estimated regression coefficient $=-0.135,95 \% \mathrm{CI}-0.233$ to -0.037) and less time in MPA with bouts of at least 10 minutes (estimated regression coefficient $=-0.192,95 \%$ CI -0.321 to -0.064 ) (Table 5). The explained variance of all studied patient characteristics was highest for the CAT $(62 \%)$. 
Table 4 Associations between health status, dyspnea severity, anxiety and depression, airflow limitation, lung hyperinflation, inflammatory parameters, exacerbations and morning symptom severity

\begin{tabular}{|c|c|c|c|c|c|c|c|c|}
\hline \multirow[t]{2}{*}{ Outcome } & \multicolumn{4}{|c|}{ Morning symptom score ${ }^{a}(\mathrm{~N}=\mathbf{8 0})$} & \multicolumn{4}{|c|}{ Adjusted $^{\mathrm{b}}$ morning symptom score ${ }^{\mathrm{a}}(\mathrm{N}=\mathbf{8 0})$} \\
\hline & $R^{2}$ & $\begin{array}{l}\text { Regression } \\
\text { coefficient }\end{array}$ & $95 \% \mathrm{Cl}$ & $p$-value & $R^{2}$ & $\begin{array}{l}\text { Regression } \\
\text { coefficient }\end{array}$ & $95 \% \mathrm{Cl}$ & $p$-value \\
\hline CAT & 0.62 & 1.268 & I.042; I.494 & $<0.00 \mathrm{I}$ & 0.67 & 1.194 & $0.923 ; 1.465$ & $<0.001$ \\
\hline $\mathrm{mMRC}$ & 0.30 & 4.991 & $3.270 ; 6.712$ & $<0.001$ & 0.47 & 4.193 & $2.384 ; 6.002$ & $<0.001$ \\
\hline HADSc & 0.33 & 1.152 & $0.776 ; 1.528$ & $<0.001$ & 0.51 & 1.098 & $0.706 ; 1.490$ & $<0.001$ \\
\hline $\mathrm{FEV}_{1}(\% \text { predicted })^{\mathrm{b}}$ & 0.06 & -0.173 & $-0.325 ;-0.021$ & 0.026 & 0.35 & -0.170 & $-0.324 ;-0.017$ & 0.030 \\
\hline $\mathrm{RV} / \mathrm{TLC}^{c, \mathrm{~d}}$ & 0.04 & 0.094 & $-0.019 ; 0.207$ & 0.10 & 0.34 & 0.063 & $-0.050 ; 0.176$ & 0.27 \\
\hline $\mathrm{HsCRP}$ & 0.03 & 0.456 & $-0.128 ; 1.039$ & 0.12 & 0.31 & 0.242 & $-0.319 ; 0.804$ & 0.39 \\
\hline Leucocytes & 0.02 & 0.656 & $-0.383 ; 1.695$ & 0.21 & 0.31 & 0.217 & $-0.80 \mathrm{I} ; \mathrm{I} .236$ & 0.67 \\
\hline Eosinophils & 0.06 & -14.68 & $-28.14 ;-1.231$ & 0.033 & 0.32 & -7.772 & $-20.575 ; 5.032$ & 0.23 \\
\hline $\begin{array}{l}\text { At least one exacerbation } \\
\text { in the previous } 12 \text { months }\end{array}$ & 0.07 & 6.302 & 1.239; 11.37 & 0.015 & 0.30 & 01.112 & $-8.539 ; 6.314$ & 0.77 \\
\hline
\end{tabular}

Notes: a Morning symptoms were assessed with the PRO-Morning COPD Systems Questionnaire; badjusted for gender, age, ethnicity, body mass index, smoking, number of exacerbations, LAMA use, employment and comorbidity; ffor some variables data were missing: HADS (two patients did not fill out all questions about anxiety); body plethysmography (three patients were not able to produce reproducibility curves and one patient had claustrophobia); ${ }^{d}$ post-bronchodilator.

Abbreviations: $\mathrm{Cl}$, confidence interval; CAT, COPD assessment test; FEV , forced expiratory volume in I second; HADS, hospital anxiety and depression scale; hsCRP, high sensitive C-reactive protein; LAMA, long-acting muscarinic antagonist; mMRC, modified Medical Research Council; $R^{2}$, explained variance; RV, residual volume; TLC, total lung capacity.

\section{Sensitivity analysis}

When the CAT was used instead of the mMRC scale to classify COPD severity, differences in the morning symptom severity were still present between the different GOLD stages. In addition, there was also a significant difference in morning symptom severity between patients with COPD GOLD $\mathrm{B}$ and D (Figure S1).

\section{Discussion}

In the present study, morning symptom severity was assessed in COPD GOLD A, B, C and D patients. Furthermore, the association between patient characteristics (with special focus on physical activity) and morning symptom severity was studied. As far as we know, this is the first time the relationship between morning symptom severity and objective

Table 5 Associations between minutes in active and inactive time, periods in activity and inactivity and morning symptom severity

\begin{tabular}{|c|c|c|c|c|c|c|c|c|}
\hline \multirow[t]{2}{*}{ Outcome } & \multicolumn{4}{|c|}{ Morning symptom score $(\mathbf{N}=\mathbf{7} I)^{b}$} & \multicolumn{4}{|c|}{ Adjusted $^{\mathrm{c}}$ morning symptom score ${ }^{\mathrm{a}}(\mathrm{N}=7 \mathrm{I})^{\mathrm{b}}$} \\
\hline & $\overline{R^{2}}$ & $\begin{array}{l}\text { Regression } \\
\text { coefficient }\end{array}$ & $95 \% \mathrm{Cl}$ & $p$-value & $\overline{R^{2}}$ & $\begin{array}{l}\text { Regression } \\
\text { coefficient }\end{array}$ & $95 \% \mathrm{Cl}$ & $\overline{p \text {-value }}$ \\
\hline Steps & 0.09 & -0.001 & $-0.002 ; 0.000$ & 0.013 & 0.30 & -0.001 & $-0.002 ; 0.000$ & 0.043 \\
\hline Total active time ${ }^{d}$ & 0.03 & -0.019 & $-0.047 ; 0.009$ & 0.18 & 0.25 & -0.010 & $-0.039 ; 0.020$ & 0.52 \\
\hline Total inactive time ${ }^{\mathrm{e}}$ & 0.04 & 0.022 & $-0.005 ; 0.049$ & 0.11 & 0.26 & 0.012 & $-0.018 ; 0.041$ & 0.43 \\
\hline Light activities ${ }^{f}$ & 0.001 & 0.011 & $-0.073 ; 0.095$ & 0.79 & 0.26 & 0.035 & $-0.050 ; 0.119$ & 0.42 \\
\hline Moderate activities ${ }^{f}$ & 0.08 & -0.082 & $-0.150 ;-0.014$ & 0.019 & 0.27 & -0.052 & $-0.150 ; 0.019$ & 0.15 \\
\hline Vigorous activities $^{f}$ & 0.03 & -0.130 & $-0.327 ; 0.067$ & 0.19 & 0.26 & -0.097 & $-0.306 ; 0.112$ & 0.36 \\
\hline Time in MVPA with bouts ${ }^{f}$ & 0.13 & -0.151 & $-0.244 ;-0.058$ & $<0.001$ & 0.33 & -0.135 & $-0.233 ;-0.037$ & $<0.001$ \\
\hline Time in moderate activity with bouts ${ }^{f}$ & 0.15 & -0.218 & $-0.344 ;-0.092$ & $<0.001$ & 0.35 & -0.192 & $-0.321 ;-0.064$ & $<0.001$ \\
\hline Time in vigorous activity with bouts ${ }^{f}$ & 0.03 & -0.170 & $-0.387 ; 0.047$ & 0.12 & 0.26 & -0.127 & $-0.357 ; 0.103$ & 0.27 \\
\hline Number of periods in inactive time ${ }^{e}$ & 0.01 & -0.030 & $-0.096 ; 0.036$ & 0.37 & 0.25 & 0.003 & $-0.069 ; 0.076$ & 0.92 \\
\hline Number of periods in active time ${ }^{d}$ & 0.04 & -0.003 & $-0.006 ; 0.001$ & 0.10 & 0.25 & -0.001 & $-0.004 ; 0.003$ & 0.71 \\
\hline Periods in walking time $\leq 10$ seconds & 0.06 & -0.021 & $-0.040 ;-0.002$ & 0.034 & 0.26 & -0.011 & $-0.032 ; 0.009$ & 0.28 \\
\hline Periods in walking time $10-20$ seconds & 0.04 & -0.061 & $-0.134 ; 0.012$ & 0.099 & 0.26 & -0.028 & $-0.105 ; 0.050$ & 0.48 \\
\hline Periods in walking time $>20$ seconds & 0.07 & -0.133 & $-0.249 ;-0.017$ & 0.026 & 0.29 & -0.111 & $-0.232 ; 0.010$ & 0.07 \\
\hline
\end{tabular}

Notes: a Morning symptoms were assessed with the PRO-Morning COPD Systems Questionnaire; bdata from patients with an adverse event $(\mathrm{N}=8)$ or patients with no valid data from accelerometry $(\mathrm{N}=\mathrm{I})$ were excluded and analyses were performed on data from $7 \mathrm{I}$ patients; ' adjusted for gender, age, ethnicity, body mass index, smoking, number of exacerbations, LAMA use, employment and comorbidity; ' active: standing, shuffling and walking combined; einactive: sitting and lying combined; light: 1.5 -3.0 MET, moderate: 3.0-6.0 MET, vigorous: 6.0-9.0 MET.

Abbreviations: $\mathrm{Cl}$, confidence interval; LAMA, long-acting muscarinic antagonist; MET, metabolic equivalent task; MVPA, moderate-to-vigorous physical activity; $R^{2}$, explained variance. 
measures of the physical activity by triaxial accelerometry has been studied. In the present study, patients with overall more symptomatic COPD had significantly higher morning symptom scores. Lower health status, higher symptomatic burden, increased anxiety and depression, lower $\mathrm{FEV}_{1}$, fewer steps a day and less time in moderate and vigorous physical activity with bouts of at least 10 minutes that was objectively measured by accelerometry were associated with morning symptom severity.

Morning symptom scores were higher in patients with GOLD B and D compared with GOLD A and C stages. However, morning symptoms were not limited to more advanced COPD stages and were also present in patients of group A. These results are in line with the first and so far only study that described the relation between the occurrence of morning symptoms and severity of COPD with GOLD A-D classification. ${ }^{7}$ In that study, patterns of morning symptom occurrence was more associated with the GOLD A-D categorization compared to GOLD 1-4 classification. GOLD 1-4 classification is based only on airflow limitation, whereas in GOLD A-D a combination of airflow limitation, general symptoms and exacerbations are used to classify the patients. Previous studies have shown associations between morning symptoms and airflow limitation, ${ }^{2,30}$ general symptoms ${ }^{2,3}$ and COPD exacerbations in the previous 12 months. ${ }^{30-32}$ In the current study, $\mathrm{FEV}_{1}$ and symptoms measured with the mMRC were significantly associated with the severity of morning symptoms. Furthermore, unadjusted analyses showed an association between exacerbations in the previous 12 months and morning symptom severity. Since overall symptoms and exacerbations, which are included in the GOLD A-D scheme, are associated with morning symptoms, we believe that GOLD A-D relates more closer to morning symptoms than GOLD 1-4. The sensitivity analyses showed that the differences in morning symptom severity between GOLD A, B, C and D groups were independent of the symptoms scale that was used and no difference between mMRC and CAT was found. Overall, our results are supported by the finding that the occurrence of nighttime symptoms was more closely related to the GOLD A-D classification than the GOLD 1-4 classification. ${ }^{33}$

In the present study, the occurrence of morning symptoms was higher than that reported in other studies. The use of a different morning symptom questionnaire could be responsible for the higher occurrence in the current study. ${ }^{5}$ The prevalence of morning symptoms in the present study is in line with a previous trial that studied morning symptoms in more than 3,000 COPD patients. ${ }^{34}$ In that study, $94.4 \%$ of patients with moderate to severe COPD suffered from morning symptoms, measured with Early-Morning Symptoms of COPD Instrument. In the current study, the PRO-Morning COPD Symptoms Questionnaire was used. One previous randomized trial used this questionnaire and found a mean morning symptom severity score of $16.7 .{ }^{17}$ The MODAS showed a slightly higher mean morning symptom score. This could be due to a slightly different COPD population (lower $\mathrm{FEV}_{1}$, fewer males, less current smokers) or the unknown variance of the morning symptom score. Overall, morning symptoms score are relatively low. For example, analyses on 3,394 COPD GOLD II and III patients have shown a mean morning symptom score of 1.3 (minimum 0 , maximum 4 ) ${ }^{34}$ Furthermore, we know from previous research that patients underestimated their symptoms and one-third of patients who describe their symptoms as being mild to moderate are not able to leave the house due to breathlessness. ${ }^{35} \mathrm{We}$ think that the PRO-Morning COPD Symptoms Questionnaire can be a suitable tool to assess morning symptoms. Nevertheless, this questionnaire needs to be validated in further studies. Using a validated questionnaire with cutoff scores might help to indicate whether a score of 17.9 could be seen as high or as low impact.

Previous studies that reported the association between morning symptoms and physical activity used self-reported physical activity questionnaires to evaluate physical activity. 2,3,6,14,30,34,36,37 However, it is known that self-reported outcomes show discrepancies to objective measured outcomes, ${ }^{38}$ and therefore we assessed physical activity using an established activity monitor. ${ }^{19,39}$ Indeed, when analyzing the data retrieved from these monitors we found a relationship between objectively measured physical activity and an increase in morning symptom severity. More specifically, an association between fewer steps a day, less time in MVPA with bouts of at least 10 minutes and less time in MPA with bouts of at least 10 minutes and increase in morning symptom severity was found. Interestingly, when we do not take these bouts into account, time in MPA and MVPA was not associated with morning symptom severity. This means that COPD patients with higher morning symptom scores are able to perform physical activity of moderate and vigorous intensity similar to those with less severe morning symptoms, but they rarely perform this activity longer than 10 minutes at a time. We suggest that these patients do not perform activities for increased amounts of time as an adaptation to, for example, avoid symptoms, and they are therefore not used to being active for more than 10 minutes in moderate or vigorous activity. For light-intensity physical activity, 
no association with morning symptom severity was found. Sufficient physical activity is important for COPD patients because the lack of it is associated with more exacerbations, hospitalizations, all-cause mortality ${ }^{12}$ and lower quality of life. ${ }^{13}$ These results together underline the importance of morning symptoms and physical activity. Together, they seem to be a new important target for therapy.

The association between lower health status, ${ }^{2,7,30,37,40}$ more dyspnea, ${ }^{2,3}$ increased anxiety and depression, 2,30,37,40 lower $\mathrm{FEV}_{1}^{2,30}$ and morning symptoms have been described earlier. The association between morning symptoms and overall symptoms might appear to be trivial; however, previous studies have shown that symptoms can vary over the day and therefore more precise assessment of symptoms seems necessary. The present study confirms this; the CAT does not fully cover morning symptoms with an explained variance of $62 \%$. Based on this, we recommend assessing morning symptoms separately from general symptoms in COPD patients, especially in those with more symptomatic COPD.

A strength of this study is the adjustment for multiple confounders in the regression analysis, which was omitted in previous studies. ${ }^{2,37}$ Furthermore, we believe that this study population is representative of the COPD population since patients were recruited from a variety of sources, namely, a university medical center, a regional hospital and recruitment via flyers. This resulted in a heterogeneous COPD patient group. However, the exclusion of COPD GOLD I patients can be seen as a limitation. We expect that including COPD GOLD I patients would result in a slightly lower mean morning symptom score since morning symptoms are also present in mild COPD. ${ }^{2}$ However, in this study we decided to focus on more symptomatic patients since it was a crosssectional study that explored factors that were associated with morning symptoms. One other limitation of this study is that there might be selection bias, since nonparticipants were most likely patients who were not able to come to the study center in the morning. This might have resulted in an underestimation of morning symptoms in the overall COPD population. A limitation for the use of a MoveMonitor was the non-water resistance. For some patients, taking a shower is the most intensive physical activity of the day, and this has not been measured. This resulted in an underestimation of active time. Furthermore, patients were not blinded for the accelerometer. This could have resulted in increased activity since patients felt they were being watched and would not be categorized as "inactive." However, patients took a comparable amount or fewer steps than reported in previous studies, ${ }^{41,42}$ suggesting that patients in the MODAS did not adapt their lifestyle to the study. Furthermore, with this observational study design it is not possible to prove causality. Therefore, we are not able to state whether limitation in physical activity is a result of morning symptoms, or if it is the other way around; that is, physical inactivity causes deconditioning which results in an increase of morning symptoms.

\section{Conclusion}

Patients with overall more symptomatic COPD have significant higher morning symptom scores. Furthermore, morning symptoms were associated with important clinical outcomes: lower health status, more symptoms, increased anxiety and depression, fewer steps a day, less time in moderate and vigorous physical activity with bouts of at least 10 minutes and lower $\mathrm{FEV}_{1}$. This was the first study that evaluated the relation between morning symptom severity and objective measures of physical activity by triaxial accelerometry. Morning symptoms should be assessed more precisely in addition to assessment by general COPD-specific questionnaires, especially in those with more symptomatic COPD. Therefore, there is need for the validation of a morning symptom questionnaire. In addition, more research is needed on potential therapies to improve morning symptoms, for example, with the improvement of (a combination of) health status, symptoms, anxiety and depression, steps a day, time in moderate and vigorous physical activity with bouts of at least 10 minutes and $\mathrm{FEV}_{1}$.

\section{Acknowledgments}

We thank Steven JHA McDowell for critically reading the manuscript. This study was supported by Novartis with an unrestricted research grant.

\section{Disclosure}

ARvB, MJK and NHC report no conflicts of interest in this work. CT reports grants and personal fees from Novartis during the conduct of the study and personal fees from Boehringer Ingelheim, Astra Zeneca, Teva, and Chiesi outside the submitted work.

\section{References}

1. Murray CJ, Barber RM, Foreman KJ, et al. Global, regional, and national disability-adjusted life years (DALYs) for 306 diseases and injuries and healthy life expectancy (HALE) for 188 countries, 1990-2013: quantifying the epidemiological transition. Lancet. 2015;386(10009): 2145-2191.

2. Miravitlles M, Worth H, Soler Cataluna JJ, et al. Observational study to characterise 24-hour COPD symptoms and their relationship with patient-reported outcomes: results from the ASSESS study. Respir Res. 2014;15:122.

3. Partridge MR, Karlsson N, Small IR. Patient insight into the impact of chronic obstructive pulmonary disease in the morning: an internet survey. Curr Med Res Opin. 2009;25(8):2043-2048. 
4. van Buul AR, Kasteleyn MJ, Chavannes NH, Taube C. Association between morning symptoms and physical activity in COPD: a systematic review. Eur Respir Rev. 2017;26(143):160033.

5. van Buul AR, Kasteleyn MJ, Chavannes NH, Taube C. Morning symptoms in COPD: a treatable yet often overlooked factor. Expert Rev Respir Med. 2017;11(4):311-322.

6. Kim YJ, Lee BK, Jung CY, et al. Patient's perception of symptoms related to morning activity in chronic obstructive pulmonary disease: the SYMBOL Study. Korean J Intern Med. 2012;27(4):426-435.

7. Tsiligianni I, Metting E, van der Molen T, Chavannes N. Morning and night symptoms in primary care COPD patients: a cross-sectional and longitudinal study. An UNLOCK study from the IPCRG. NPJ Prim Care Respir Med. 2016;26:16040.

8. Pitta F, Troosters T, Spruit MA, Probst VS, Decramer M, Gosselink R. Characteristics of physical activities in daily life in chronic obstructive pulmonary disease. Am J Respir Crit Care Med. 2005;171(9): 972-977.

9. Troosters T, Sciurba F, Battaglia S, et al. Physical inactivity in patients with COPD: a controlled multi-center pilot-study. Respir Med. 2010;104(7):1005-1011.

10. Donaire-Gonzalez D, Gimeno-Santos E, Balcells E, et al. Physical activity in COPD patients: patterns and bouts. Eur Respir J. 2013;42(4): 993-1002.

11. Brawner CA, Churilla JR, Keteyian SJ. Prevalence of physical activity is lower among individuals with chronic disease. Med Sci Sports Exerc. 2016;48(6):1062-1067.

12. Garcia-Aymerich J, Lange P, Benet M, Schnohr P, Anto JM. Regular physical activity reduces hospital admission and mortality in chronic obstructive pulmonary disease: a population based cohort study. Thorax 2006;61(9):772-778.

13. Esteban C, Quintana JM, Aburto M, et al. Impact of changes in physical activity on health-related quality of life among patients with COPD. Eur Respir J. 2010;36(2):292-300.

14. O'Hagan P, Chavannes NH. The impact of morning symptoms on daily activities in chronic obstructive pulmonary disease. Curr Med Res Opin. 2014;30(2):301-314.

15. Global Initiative for Chronic Obstructive Lung Disease. Global Strategy for the Diagnosis, Management and prevention of COPD; 2017 [updated 2017]. Available from: http://www.goldcopd.org/. Accessed: May 16, 2017.

16. Anthonisen NR, Manfreda J, Warren CP, Hershfield ES, Harding GK, Nelson NA. Antibiotic therapy in exacerbations of chronic obstructive pulmonary disease. Ann Intern Med. 1987;106(2):196-204.

17. Marin JM, Beeh KM, Clemens A, et al. Early bronchodilator action of glycopyrronium versus tiotropium in moderate-to-severe COPD patients: a cross-over blinded randomized study (Symptoms and Pulmonary function in the moRnING). Int J Chron Obstruct Pulmon Dis. 2016;11:1425-1434.

18. Haskell WL, Lee IM, Pate RR, et al. Physical activity and public health: updated recommendation for adults from the American College of Sports Medicine and the American Heart Association. Med Sci Sports Exerc. 2007;39(8):1423-1434.

19. Rabinovich RA, Louvaris Z, Raste Y, et al. Validity of physical activity monitors during daily life in patients with COPD. Eur Respir J. 2013;42(5):1205-1215.

20. Van Remoortel H, Giavedoni S, Raste Y, et al. Validity of activity monitors in health and chronic disease: a systematic review. Int J Behav Nutr Phys Act. 2012;9:84.

21. Van Remoortel H, Raste Y, Louvaris Z, et al. Validity of six activity monitors in chronic obstructive pulmonary disease: a comparison with indirect calorimetry. PloS one. 2012;7(6):e39198.

22. Bestall JC, Paul EA, Garrod R, Garnham R, Jones PW, Wedzicha JA. Usefulness of the Medical Research Council (MRC) dyspnoea scale as a measure of disability in patients with chronic obstructive pulmonary disease. Thorax. 1999;54(7):581-586.
23. Jones PW, Harding G, Berry P, Wiklund I, Chen WH, Kline Leidy N. Development and first validation of the COPD Assessment Test. Eur Respir J. 2009;34(3):648-654.

24. Charlson ME, Pompei P, Ales KL, MacKenzie CR. A new method of classifying prognostic comorbidity in longitudinal studies: development and validation. J Chronic Dis. 1987;40(5):373-383.

25. Miller MR, Hankinson J, Brusasco V, et al. Standardisation of spirometry. Eur Respir J. 2005;26(2):319-338.

26. Quanjer PH, Stanojevic S, Cole TJ, et al. Multi-ethnic reference values for spirometry for the 3-95-yr age range: the global lung function 2012 equations. Eur Respir J. 2012;40(6):1324-1343.

27. Criee CP, Sorichter S, Smith HJ, et al. Body plethysmography - its principles and clinical use. Respir Med. 2011;105(7):959-971.

28. Casanova C, Marin JM, Martinez-Gonzalez C, et al. New GOLD classification: longitudinal data on group assignment. Respir Res. 2014; $15: 3$

29. Jones PW, Nadeau G, Small M, Adamek L. Characteristics of a COPD population categorised using the GOLD framework by health status and exacerbations. Respir Med. 2014;108(1):129-135.

30. Roche N, Small M, Broomfield S, Higgins V, Pollard R. Real world COPD: association of morning symptoms with clinical and patient reported outcomes. COPD. 2013;10(6):679-686.

31. Miravitlles M, Worth H, Soler-Cataluna JJ, et al. The relationship between 24-hour symptoms and copd exacerbations and healthcare resource use: results from an observational study (ASSESS). COPD. 2016;13(5):561-568.

32. Tsiligianni I, Metting E, van der Molen T, Chavannes N, Kocks J. Morning and night symptoms in primary care COPD patients: a crosssectional and longitudinal study. An UNLOCK study from the IPCRG. NPJ Prim Care Respir Med. 2016;26:16040.

33. Lange P, Marott JL, Vestbo J, Nordestgaard BG. Prevalence of nighttime dyspnoea in COPD and its implications for prognosis. Eur Respir J. 2014;43(6):1590-1598.

34. Bateman ED, Chapman KR, Singh D, et al. Aclidinium bromide and formoterol fumarate as a fixed-dose combination in COPD: pooled analysis of symptoms and exacerbations from two six-month, multicentre, randomised studies (ACLIFORM and AUGMENT). Respir Res. 2015;16:92.

35. Rennard S, Decramer M, Calverley PM, et al. Impact of COPD in North America and Europe in 2000: subjects' perspective of Confronting COPD International Survey. Eur Respir J. 2002;20(4):799-805.

36. Kessler R, Partridge MR, Miravitlles M, et al. Symptom variability in patients with severe COPD: a pan-European cross-sectional study. Eur Respir J. 2011;37(2):264-272.

37. Stephenson JJ, Cai Q, Mocarski M, Tan H, Doshi JA, Sullivan SD. Impact and factors associated with nighttime and early morning symptoms among patients with chronic obstructive pulmonary disease. Int $J$ Chron Obstruct Pulmon Dis. 2015;10:577-586.

38. Thyregod M, Bodtger U. Coherence between self-reported and objectively measured physical activity in patients with chronic obstructive lung disease: a systematic review. Int J Chron Obstruct Pulmon Dis. 2016;11:2931-2938.

39. Van Hees VT, Slootmaker SM, De Groot G, Van Mechelen W, Van Lummel RC. Reproducibility of a triaxial seismic accelerometer (DynaPort). Med Sci Sports Exerc. 2009;41(4):810-817.

40. Soler-Cataluna JJ, Sauleda J, Valdes L, et al. Prevalence and perception of 24-hour symptom patterns in patients with stable chronic obstructive pulmonary disease in Spain. Arch Bronconeumol. 2016;52(6): 308-315.

41. Waschki B, Kirsten AM, Holz O, et al. Disease progression and changes in physical activity in patients with chronic obstructive pulmonary disease. Am J Respir Crit Care Med. 2015;192(3):295-306.

42. Watz H, Waschki B, Boehme C, Claussen M, Meyer T, Magnussen H. Extrapulmonary effects of chronic obstructive pulmonary disease on physical activity: a cross-sectional study. Am J Respir Crit Care Med. 2008;177(7):743-751. 


\section{Supplementary materials}

To categorize the patients, the first step was to assess the symptom burden with the modified Medical Research Council (mMRC) scale. A low symptom burden was defined as mMRC 0 to 1 and a high symptom burden as 2 or higher. Moreover, the exacerbation risk was evaluated by airflow obstruction, number of exacerbations in the previous year and number of exacerbations leading to hospital admission in the previous year. A low risk was defined as a forced expiratory volume in 1 second $\left(\mathrm{FEV}_{1}\right) \geq 50 \%$ and $<2$ exacerbations a year and no hospital admission due to exacerbation of COPD; a high risk was defined as a $\mathrm{FEV}_{1}<50 \%$ or $\geq 2$ exacerbations in the previous year or $\geq 1$ hospital admission due to exacerbation of COPD. Group A was defined as a low symptom burden with low risk; group B as high symptom burden with low risk; group $\mathrm{C}$ as low symptom burden with high risk and group D as high symptom burden with high risk.

Table SI Adverse events during study period

\begin{tabular}{ll}
\hline Adverse event & $\begin{array}{l}\text { Number } \\
\text { of patients }\end{array}$ \\
\hline Pain in the hand & 2 \\
Migraine plus hematuria & $\mathrm{I}$ \\
Flu & $\mathrm{I}$ \\
Pneumonia & $\mathrm{I}$ \\
Exacerbation COPD that was treated by the GP & $\mathrm{I}$ \\
Rhinosinusitis & $\mathrm{I}$ \\
Exhausted and dyspneic for multiple days due to \\
the study visit
\end{tabular}

Abbreviation: GP, general practitioner.

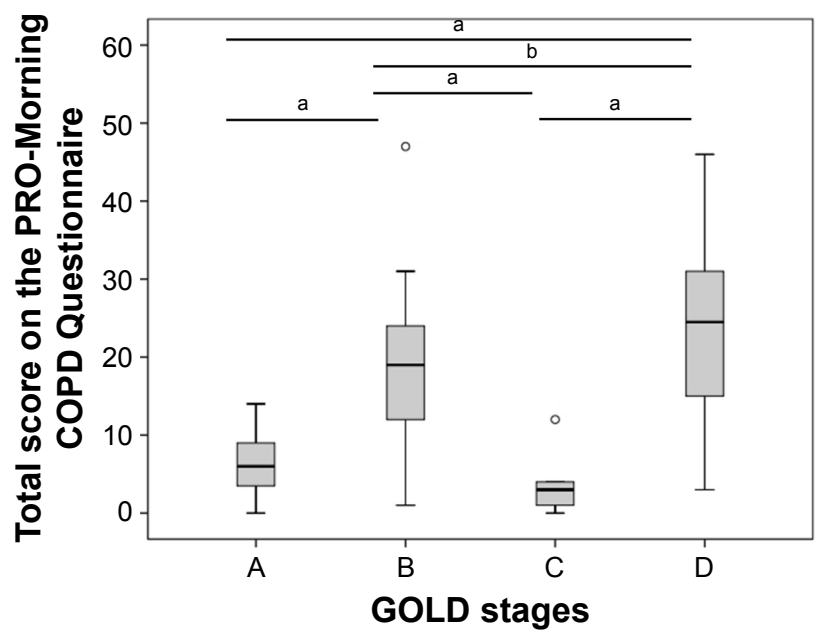

Figure SI Morning symptom scores in COPD GOLD A, B, C and D patients, categorization with CAT.

Notes: Morning symptoms scores were significantly different between patients with COPD GOLD A $6.3( \pm 4.4), B \quad 18.4( \pm 10.1), C 4.0( \pm 4.7)$ and D $23.6( \pm I I .0)$ $(F[d f]=13.0$ [79], $p<0.01)$; COPD GOLD A $(N=12), B(N=29), C(N=5)$ and $D$ $(\mathrm{N}=34) ;{ }^{a} p<0.01$, ${ }^{b} p<0.05$.

Abbreviations: CAT, COPD Assessment Test; GOLD, Global Initiative for Chronic Obstructive Lung Disease.
International Journal of COPD

\section{Publish your work in this journal}

The International Journal of COPD is an international, peer-reviewed journal of therapeutics and pharmacology focusing on concise rapid reporting of clinical studies and reviews in COPD. Special focus is given to the pathophysiological processes underlying the disease, intervention programs, patient focused education, and self management protocols.

\section{Dovepress}

This journal is indexed on PubMed Central, MedLine and CAS. The manuscript management system is completely online and includes a very quick and fair peer-review system, which is all easy to use. Visit http://www.dovepress.com/testimonials.php to read real quotes from published authors. 